\title{
Extralevator abdominoperineal excision (ELAPE) for rectal cancer-short-term results from the Swedish Colorectal Cancer Registry. Selective use of ELAPE warranted
}

\author{
Mattias Prytz • Eva Angenete • Jan Ekelund • \\ Eva Haglind
}

Accepted: 12 June 2014 / Published online: 21 June 2014

(C) The Author(s) 2014. This article is published with open access at Springerlink.com

\begin{abstract}
Purpose Local recurrences are more common after abdominoperineal excision (APE) than after anterior resection of rectal cancer. Extralevator APE was introduced to address this problem. This prospective registry-based population study aims to investigate the efficacy of extralevator APE (ELAPE) in improving short-term oncological outcome.

Methods All Swedish patients operated with any kind of abdominoperineal excision and registered in the Swedish Rectal Cancer Registry 2007-2009 were included $(n=1,397)$ and analyzed with emphasis on the perineal part of the operation. Short-term perioperative and oncological results were collected from the registry.

Results Extralevator APE did not result in fewer intraoperative perforations or involved circumferential resection margins as compared to standard APE for the entire group. Intraoperative perforations were significantly fewer for patients with low tumours $(\leq 4 \mathrm{~cm})$ (ELAPE: $n=28 / 386$ versus APE: $n=9 / 58)(p=0.043)$ and for early (T0-T2) T-stages (ELAPE: $n=3 / 172$ versus APE: $n=6 / 75)(p=0.025)$. There were significantly more post-operative wound infections for ELAPE than for APE $(n=106(20.4 \%)$ versus $n=25(12.0 \%), p=0.011)$.
\end{abstract}

Presented, in part, to the annual meeting of the Swedish Surgical Society, Uppsala, Sweden, August 2013 and the annual meeting of the European Society of Coloproctology, Belgrade, Serbia, September 2013.

M. Prytz $(\bowtie)$

Department of Surgery, NU Hospital Group, Trollhättan, Sweden

e-mail: mattias.prytz@vgregion.se

E. Angenete $\cdot$ E. Haglind

Department of Surgery, Sahlgrenska University Hospital/Östra,

Gothenburg, Sweden

M. Prytz $\cdot$ E. Angenete $\cdot$ J. Ekelund $\cdot$ E. Haglind

Scandinavian Surgical Outcomes Research Group (SSORG) and the

Sahlgrenska Academy, University of Gothenburg, Gothenburg,

Sweden
Conclusions The short-term results indicate that selective use of extralevator APE can be warranted, for example, for subgroups with low tumours. In conclusion, selective use of the extralevator APE is advocated as not all patients seem to benefit from the technique, and there are significantly more short-term complications after extralevator APE.

Keywords APE $\cdot$ ELAPE $\cdot$ Colorectal cancer

\section{Introduction}

Abdominoperineal excision (APE) is the surgical treatment for patients with distal rectal cancer in whom an anterior resection with anastomosis (AR) cannot be performed [1,2]. Studies show that the overall prognosis for these patients is worse than that for patients undergoing AR and that the local recurrence rates are higher [3-9]. In order to address this problem, a more extensive surgical procedure has been proposed [10-14]. The aim of the procedure - described elsewhere and here referred to as the extralevator APE (ELAPE) ] - is to create a cylindrical specimen without a 'waist' in order to minimize the risk of a tumour involvement of the circumferential resection margin (CRM) and to reduce the risk of intraoperative tumour perforation (Fig. 1). Several studies have reported that ELAPE is superior to standard APE [10, 11, 15-17], but others have reported conflicting results [18, 19], and two systematic reviews [20,21] came to different conclusions as to what extent ELAPE is oncologically superior compared to standard APE. There is one randomized, controlled trial [22] that has reported results in favour for ELAPE regarding local recurrence.

This study aims to evaluate the short-term perioperative and surrogate oncological results in a population-based cohort from the Swedish Colorectal Cancer Registry (SCRCR) following standard APE and extralevator APE. 


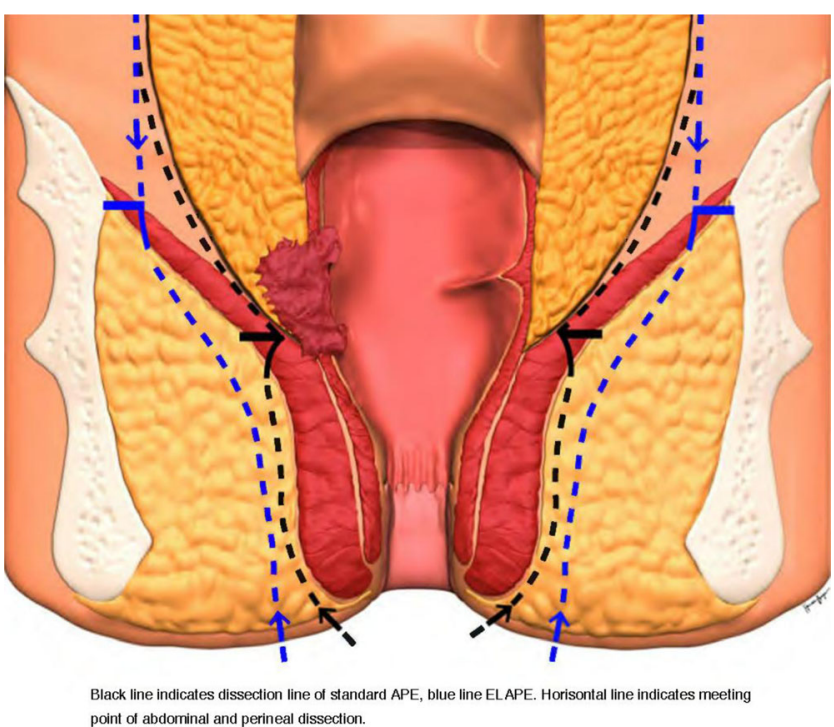

Fig. 1 Schematic anatomic picture of dissection in standard APE, as depicted by the black interrupted line, and extralevator APE (ELAPE) as depicted by the blue interrupted line

\section{Method}

A detailed description of the study has previously been published [23].

\section{Data from the Swedish Colorectal Cancer Registry}

The Swedish Colorectal Cancer Registry was established in 1995 for the registration of details regarding the treatment of rectal cancer in Sweden. All Swedish hospitals report to the registry [24]. All perioperative data in the registry on patients operated between 2007 and 2009 were retrieved including cTNM classification; level of tumour from the anal verge; patient demographics; ASA classification; pre- and postoperative adjuvant treatment; certain aspects of the operative technique such as open or laparoscopic operation, level of vascular division and perioperative complications including perioperative bleeding, perforation of the specimen and operating theatre time. Post-operative data such as pTNMclassification, CRM, distal margin, lymph node harvest and involvement were retrieved as were post-operative complications including infections, re-operations and death within 30 days.

Not included in the registry are details on the type of perineal dissection performed. Operative notes for each patient were retrieved from the hospital where the patient was operated. A clinical record form (CRF) was developed and used to register details of the perineal part of the procedure such as position of the patient, division of the levator muscle, removal of the coccyx and the perineal reconstruction. Using this information, the patients were classified as belonging to one of the following: 'APE', operated with a traditional APE,
'ELAPE', operated with an extralevator APE, 'Not stated', where the type of perineal dissection was not possible to be classified from the operating notes.

\section{Statistics}

All data were collected in a database, and statistical analysis was performed using SPSS 21.0 (IBM SPSS Inc. Armonk, NY, USA) and SAS v.9 (SAS Institute). Continuous outcome variables were compared between the groups APE and ELAPE using Wilcoxon's rank-sum test; categorical data were compared between the two groups using Fisher's exact test or the chi-squared test, as deemed appropriate.

\section{Results}

The cohort consisting of all patients registered as operated due to rectal cancer with abdominoperineal excision during 2007 2009 was identified in the SCRCR. This resulted in a total of 1,397 patients. In the flow chart (Fig. 2), exclusions are described, leaving 1,319 patients for the analysis. For the group excluded due to lack of surgical notes (4\%), clinical and demographic data from the registry did not differ compared with the patients included in the study. Clinical and demographic data for the patients are summarized in Table 1. There was a difference in pT-stage between the three groups but no difference between APE and ELAPE. Outcomes for the 'not stated' group were not analyzed further, as no information regarding the perineal part of the APE could be obtained.

Operative data on the two groups APE and ELAPE are summarized in Table 2 and show significant differences in patient positioning, resection of the coccyx, type of perineal reconstruction, type of technique used for the abdominal part of the procedure between the groups and a longer operation time for ELAPE.

Comparisons of APE and ELAPE groups showed no differences regarding the various details of the oncological result from the pathology report. Complications did not differ except for wound infections, significantly more often found in the ELAPE group (Table 3). In the analysis of subgroups, we selected tumours below and up to $4 \mathrm{~cm}$ from the anal verge and pT stages (0-2, 3 and 4, respectively). There were significantly lower rates of perforations in the ELAPE for tumours below $4 \mathrm{~cm}$ and for pT0-2, respectively, (Table 4). Regarding pT3 or pT4, there were no differences between the techniques.

\section{Discussion}

In this national study of 1,319 patients with abdominoperineal excision for rectal cancer, there was no oncological advantage 
Fig. 2 Consort diagram

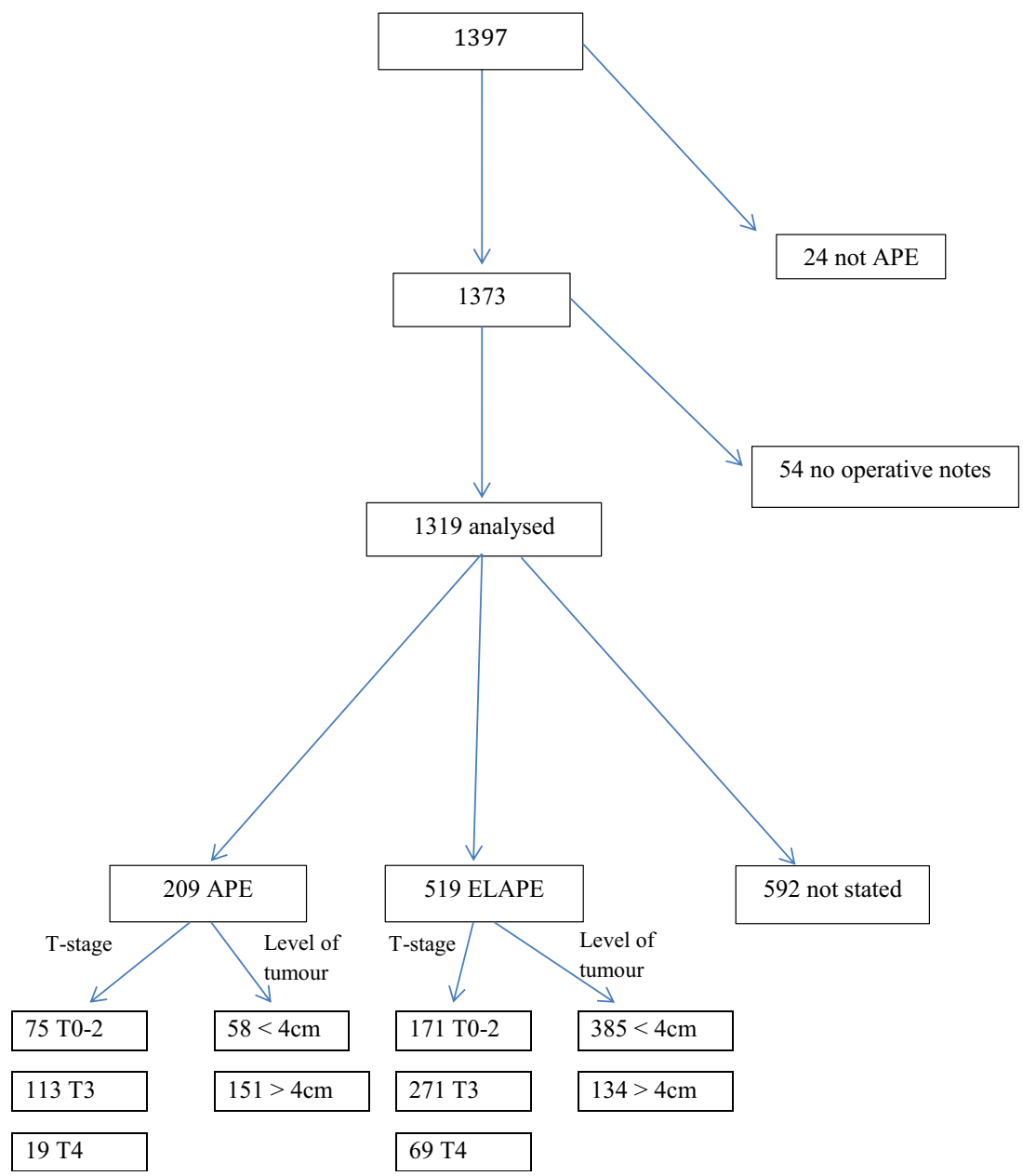

using ELAPE as compared to APE for the entire group with regard to engaged CRM and intraoperative bowel perforation. However, in subgroups consisting of the most distal tumours or with tumours staged pT0-T2, there were significantly fewer perforations in the ELAPE group. The results of the study support previous findings that ELAPE can reduce the risk of intraoperative bowel perforation, for the most distally situated tumours.

West et al. $[10,11]$ reported a lower perforation rate and fewer cases with involved CRM using ELAPE in case series in comparison with historical controls that had high rates of both perforations and involved margins. Stelzner et al. [20] concluded from their systematic review of 14 non-randomized studies from 1997 to 2011 on 'extended APE' and 50 studies on traditional APE from 1991 to 2011 that 'extended APE' had a reduced risk of intraoperative perforation. The effects on local recurrence and survival rates were not possible to be analyzed. Others have been unable to confirm these findings in case series with historical controls [18, 21], and Krishna et al. [21] concluded in their comparison of published rates of CRM involvement and intraoperative bowel perforations that there was no convincing evidence that ELAPE results were better than those for standard APE.

The only randomized controlled study by Han et al. reported a reduced recurrence rate following ELAPE after median follow-up of 29 months, suggesting that there is an oncological advantage with ELAPE as compared to traditional APE in patients with T3 and T4 tumours [22]. However, their study was small $(n=67)$, no details of external or internal validity were reported, and less than $30 \%$ of the patients received neoadjuvant treatment. Due to these methodological weaknesses, their finding may be regarded as interesting but not as conclusive.

We confirm previous findings of a higher rate of post-operative infectious complications in the ELAPE group as compared to standard APE [11, 18, 19, 22], but we found no differences between the groups regarding reoperation rate, overall complication rate or shortterm mortality. Data on wound-related infections were retrieved from the national registry, and the rates that we found were not in the higher ranges among the reported. We have, however, no reason to suspect that 


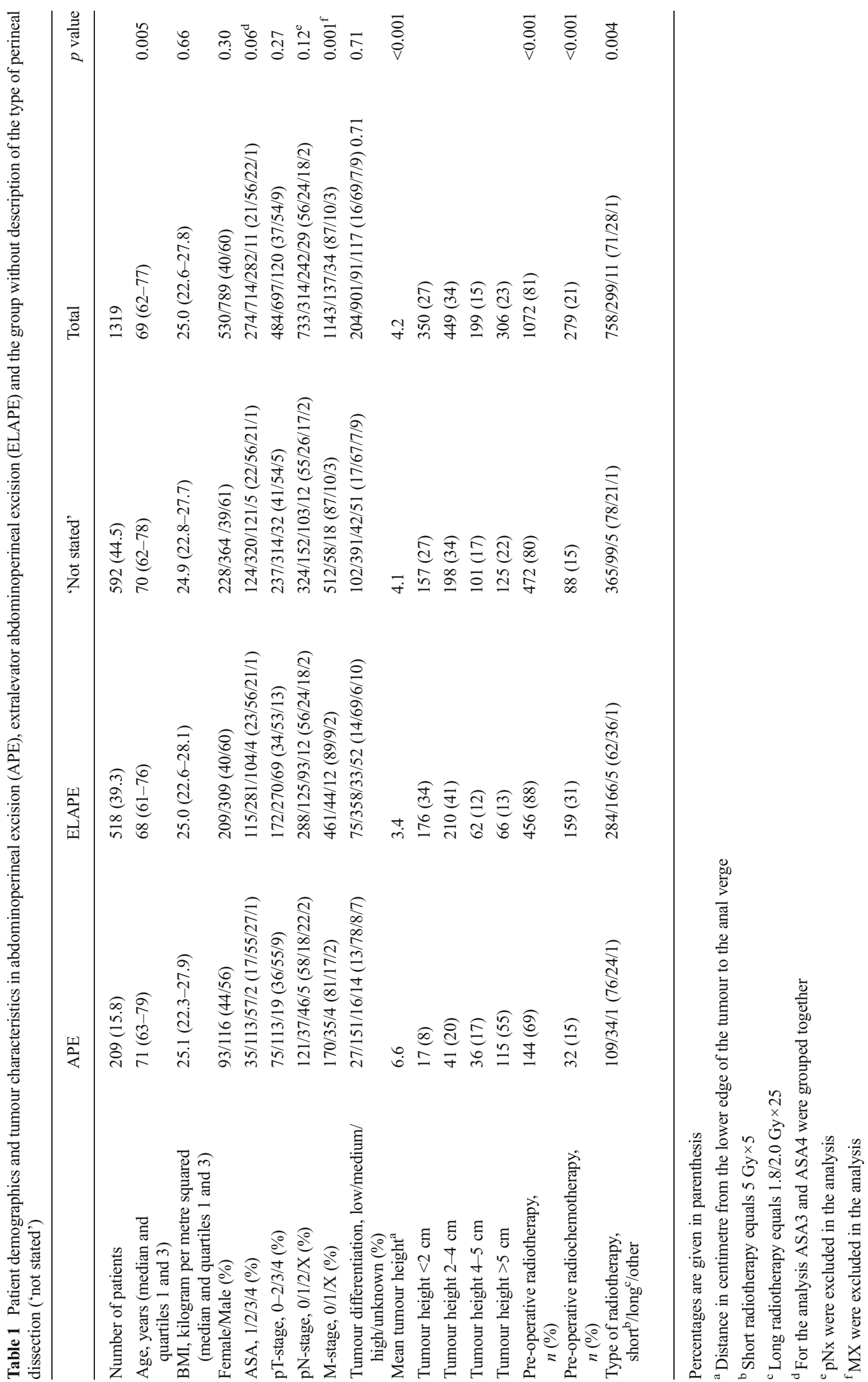


Table 2 Operative data for abdominoperineal excision (APE) and extralevator abdominoperineal excision (ELAPE)

\begin{tabular}{|c|c|c|c|}
\hline Variable & APE & ELAPE & $p$ value \\
\hline Lithotomy/Jackknife $^{\text {a }}(\%)$ & $138 / 69(66 / 33)$ & $106 / 410(21 / 79)$ & $<0.001$ \\
\hline Coccyx resection $(\%)$ & $12(6)$ & $248(48)$ & $<0.001$ \\
\hline Reconstruction: suture/mesh/flap ${ }^{\mathrm{b}}(\%)$ & $207 / 1 / 0(99 / 1 / 0)$ & $265 / 123 / 125(51 / 24 / 24)$ & $<0.001$ \\
\hline Open/Laparoscopic (\%) & $204 / 5(98 / 2)$ & $482 / 35(93 / 7)$ & $<0.02$ \\
\hline Operating theatre time, minutes (mean (SD)) & $339(116)$ & $380(151)$ & $<0.001$ \\
\hline Perioperative bleeding, millilitre (mean (SD)) & $884(995)$ & $793(831)$ & 0.43 \\
\hline
\end{tabular}

Reporting patient position, resection of the coccyx, type of perineal reconstruction, surgical technique for the abdominal operation, operating room time and perioperative bleeding

${ }^{a}$ Refers to patient positioning during the perineal part of operation

${ }^{\mathrm{b}}$ Mesh refers to any kind of absorbable/non-absorbable mesh, and flap refers to any kind of myocutaneous flap

there was any bias in reporting complications to the Swedish Colorectal Cancer Registry between the two types of procedures, and the registry did not differentiate between perineal and laparotomy wound infections.

A majority of the patients received neoadjuvant treatment, and this was more common among the patients in the ELAPE group, which could influence long-term results. Whether this, to some extent, can explain the increased wound infection rate is not clear.

A strength of our study is the cohort size and the fact that the patients included comprises $94 \%$ of all Swedish patients operated with any kind of APE in the years 2007-2009. Thus, the results are population-based. Selection bias is not a problem since practically every Swedish patient in this time frame was included. This is a strength compared to other studies with more selected case series. The Swedish Colorectal Cancer Registry is well established, has a high coverage and is validated and updated [24-26]. The cohort is prospectively registered, and the time frame of the study is short and recent. There are no comparisons to historical data.

There are, however, some weaknesses in the study. Although the coverage is high, there are still missing data. For most variables reported, the rate of missing data is small and ranges from 0 to $3 \%$ for the variables used in our study with the exception of the numerical value (in $\mathrm{mm}$ ) for the CRM, with missing data in $20 \%$ of cases, whereas the data on involvement of the CRM and intraoperative perforation were missing in less than $1 \%$. Our results regarding the absolute value of the CRM must therefore be interpreted with caution. The finding of a tendency towards a wider CRM in millimetres for the traditional APE-group may be due to a larger number of tumours situated higher in the rectum in the traditional APE group that consequently have a wider distance to the CRM - since they are to a larger extent covered by the mesorectum.

In the registry, complications were registered including reoperations, but in the time frame of our study, complications were not graded according to the Clavien-Dindo classification $[27,28]$, and the complication rates may be underreported [26]. However, the total incidence of complications is similar to other prospective studies of rectal cancer surgery [29]. The registry does not include details of the perineal part of the operation, and therefore, details of this had to be collected separately. Unfortunately, it became evident that Swedish surgeons often did not include details of the perineal dissection in their operative notes, but the remaining sample is still large.

ELAPE was already widely spread among Swedish surgeons in 2007-2009, but it was used with some discrimination for rectal cancers situated low to very low in the rectum. This selective use makes comparisons of outcomes more difficult.
Table 3 Oncological data as found in the pathology report and complications in APE and ELAPE groups

\footnotetext{
${ }^{a}$ Missing refers to missing data, number of

${ }^{\mathrm{b}}$ Wound infections includes all wound infections, abdominal and perineal wounds

${ }^{\mathrm{c}}$ Only those with infections are reported in the registry
}

\begin{tabular}{lllll}
\hline Variable & APE & ELAPE & Missing $^{\mathrm{a}}$ & $p$ value \\
\hline Bowel perforation (\%) & $23(11)$ & $40(8)$ & 3 & 0.19 \\
Involved CRM (\%) & $13(6)$ & $53(10)$ & 1 & 0.12 \\
CRM in millimetres (median (quartiles 1 and 3)) & $7(3-13)$ & $6(3-10)$ & 110 & 0.052 \\
Number of lymph node harvested, mean (SD) & $15.7(9.7)$ & $13.7(8.5)$ & 1 & 0.13 \\
30-day mortality (\%) & $5(2.4)$ & $11(2.1)$ & 14 & 0.79 \\
Complications, all (\%) & $87(41.6)$ & $238(45.9)$ & 0 & 0.32 \\
Wound infections (\%) & $25(12)$ & $106(20.5)$ & $\mathrm{c}$ & 0.008 \\
Re-operations (\%) & $19(9.1)$ & $61(11.8)$ & 1 & 0.36 \\
\hline
\end{tabular}


Table 4 Oncological data for tumour height with the lower limit $\leq 4 \mathrm{~cm}$ from the anal verge and by T-stage for APE and ELAPE groups

\begin{tabular}{|c|c|c|c|c|}
\hline Subgroup & APE & ELAPE & Missing $^{\mathrm{a}}$ & $p$ value \\
\hline Tumour height $\leq 4 \mathrm{~cm}$ & 58 & 386 & & \\
\hline Perforation, yes/no, $(\%)$ & $9 / 49(16 / 84)$ & $28 / 357(7 / 93)$ & $0 / 1$ & 0.043 \\
\hline Involved CRM, yes+uncertain/no (\%) & $4 / 54(7 / 93)$ & $36 / 350(9 / 91)$ & $0 / 0$ & 0.81 \\
\hline $\mathrm{CRM}$ in millimetres, median/mean (quartiles 1 and 3 ) & $5 / 7.3(3-10)$ & $6 / 7.8(3-10)$ & $8 / 57$ & 0.87 \\
\hline Т $0-2$ & 75 & 172 & & \\
\hline Perforation, yes/no (\%) & $6 / 69(8 / 92)$ & $3 / 168(2 / 98)$ & $0 / 1$ & 0.025 \\
\hline Involved CRM, yes+uncertain/no, $n(\%)$ & $0 / 75(0 / 100)$ & $3 / 169(2 / 98)$ & $0 / 0$ & 0.56 \\
\hline CRM in millimetres, median/mean (quartiles 1 and 3) & $10 / 11.4(5-13)$ & $10 / 11.0(5-15)$ & $20 / 42$ & 0.58 \\
\hline T 3 & 113 & 270 & & \\
\hline Perforation, yes/no (\%) & $15 / 98(13 / 87)$ & $20 / 248(7 / 93)$ & $0 / 2$ & 0.082 \\
\hline Involved CRM, yes+uncertain/no (\%) & 9/104 (8/92) & $23 / 246(9 / 91)$ & $0 / 1$ & \\
\hline $\mathrm{CRM}$ in millimetres, median/mean (quartiles 1 and 3 ) & $7 / 9.4(2-12)$ & $5 / 6.6(3-10)$ & $6 / 22$ & 0.069 \\
\hline T 4 & 19 & 69 & & \\
\hline Perforation, yes/no (\%) & 2/17 (11/89) & $17 / 52(25 / 75)$ & $0 / 0$ & 0.23 \\
\hline Involved CRM, yes+uncertain/no (\%) & $4 / 15(21 / 79)$ & $27 / 42(39 / 61)$ & $0 / 0$ & 0.18 \\
\hline CRM in millimetres, median/mean (quartiles 1 and 3 ) & $3.5 / 9.0(1.1-11)$ & $1.5 / 4.4(0-6.5)$ & $3 / 12$ & 0.13 \\
\hline
\end{tabular}

$n$ Denotes numbers throughout

${ }^{\mathrm{a}}$ Missing refers to the number of missing data

This is particularly true for T3 and even more for T4 tumours below $4 \mathrm{~cm}$ from the anal verge for which no differences between APE and ELAPE were found. On the other hand, one could argue that the ELAPE group could have included more of the advanced or ugly tumours and that the groups differed as to tumour classification as the registry did not include every detail of classification.

The finding of fewer intraoperative perforations for the early tumours (pT0-pT2) with ELAPE is somewhat unexpected and should be mentioned. A plausible hypothesis is that these perforations to some extent is due to downstaging of tumours from neoadjuvant radiotherapy which renders the tumours more fragile and susceptible to perforations when the dissection is performed in closer vicinity to the tumour-as it is with traditional APE.

Other variables that can be attributed to the results of both standard APE and ELAPE are surgeon-related variables such as level of training and annual numbers of cases. Swedish colorectal surgeons at the time could be considered well trained due to well-attended workshops on TME surgery. However, in the study, there are both high-caseload centres and centres that performed less than 10 procedures annually, so there is definitely a variation in surgeon-related competence. Since the study included all Swedish patients and centres during these years, the results should have external validity on a population basis. Another factor that might influence results is patient positioning during the perineal part of the operation; however, since the prone jackknife position is used in the majority of the ELAPE procedures and the lithotomy position in the majority of the traditional APE procedures, the influence of this factor is not possible to be analyzed.

The rapid implementation of the ELAPE technique in Sweden is interesting particularly in comparison with the implementation of laparoscopic surgery, which in sharp contrast, has not been widely spread in Sweden. At the time (2007-2009), only two small randomized controlled trials (RCTs) had reported results of laparoscopic technique [30, 31], but at present, one large RCT has reported interesting differences regarding in particular the 'oncologic outcome' for the low tumours with seeming advantages for the laparoscopic technique [29].

We conclude that selective use of extralevator abdominoperineal excision is advocated based on the short-term results of the implementation of the method in Sweden.

Acknowledgments This study was supported by grants from the Swedish Research Council (2012-1768), the Swedish Cancer Society (2013/497), Mary von Sydow Foundation, Region Västra Götaland, Sahlgrenska University Hospital (ALF grant, agreement concerning research and education of doctors) and the Health and Medical Care Committee of the Regional Executive Board, Region Västra Götaland. The authors wish to thank Mrs Tina Clough for skilled linguistic support. The authors declare no conflict of interest.

Open Access This article is distributed under the terms of the Creative Commons Attribution License which permits any use, distribution, and reproduction in any medium, provided the original author(s) and the source are credited. 


\section{References}

1. Miles WE (1971) A method of performing abdomino-perineal excision for carcinoma of the rectum and of the terminal portion of the pelvic colon (1908). CA Cancer J Clin 21(6):361-364

2. Perry WB, Connaughton JC (2007) Abdominoperineal resection: how is it done and what are the results? Clin Colon Rectal Surg 20(3):213-220

3. How P, Shihab O, Tekkis P, Brown G, Quirke P, Heald R, et al. A systematic review of cancer related patient outcomes after anterior resection and abdominoperineal excision for rectal cancer in the total mesorectal excision era. Surg Oncol 20(4):e149-55

4. Shihab OC, Brown G, Daniels IR, Heald RJ, Quirke P, Moran BJ. Patients with low rectal cancer treated by abdominoperineal excision have worse tumors and higher involved margin rates compared with patients treated by anterior resection. Dis Colon Rectum 53(1):53-6

5. Wibe A, Syse A, Andersen E, Tretli S, Myrvold HE, Soreide O (2004) Oncological outcomes after total mesorectal excision for cure for cancer of the lower rectum: anterior vs. abdominoperineal resection. Dis Colon Rectum 47(1):48-58

6. den Dulk M, Putter H, Collette L, Marijnen CA, Folkesson J, Bosset $\mathrm{JF}$ et al (2009) The abdominoperineal resection itself is associated with an adverse outcome: the European experience based on a pooled analysis of five European randomised clinical trials on rectal cancer. Eur J Cancer 45(7):1175-1183

7. den Dulk M, Marijnen CA, Putter H, Rutten HJ, Beets GL, Wiggers T et al (2007) Risk factors for adverse outcome in patients with rectal cancer treated with an abdominoperineal resection in the total mesorectal excision trial. Ann Surg 246(1):83-90

8. Marr R, Birbeck K, Garvican J, Macklin CP, Tiffin NJ, Parsons WJ et al (2005) The modern abdominoperineal excision: the next challenge after total mesorectal excision. Ann Surg 242(1):74-82

9. Nagtegaal ID, van de Velde CJ, Marijnen CA, van Krieken JH, Quirke P (2005) Low rectal cancer: a call for a change of approach in abdominoperineal resection. J Clin Oncol 23(36):9257-9264

10. West NP, Finan PJ, Anderin C, Lindholm J, Holm T, Quirke P (2008) Evidence of the oncologic superiority of cylindrical abdominoperineal excision for low rectal cancer. J Clin Oncol 26(21):3517-3522

11. West NP, Anderin C, Smith KJ, Holm T, Quirke P. Multicentre experience with extralevator abdominoperineal excision for low rectal cancer. Br J Surg 97(4):588-99

12. Holm T, Ljung A, Haggmark T, Jurell G, Lagergren J (2007) Extended abdominoperineal resection with gluteus maximus flap reconstruction of the pelvic floor for rectal cancer. Br J Surg 94(2): 232-238

13. Moore TJ, Moran BJ. Precision surgery, precision terminology: the origins and meaning of ELAPE. Colorectal Dis 14(10):1173-4

14. Shihab OC, Heald RJ, Holm T, How PD, Brown G, Quirke P, et al. A pictorial description of extralevator abdominoperineal excision for low rectal cancer. Colorectal Dis 14(10):e655-60

15. Anderin C, Martling A, Lagergren J, Ljung A, Holm T. Short term outcome after gluteus maximus myocutaneous flap reconstruction of the pelvic floor following extra-levator abdominoperineal excision of the rectum. Colorectal Dis. Oct 8
16. Anderin C, Martling A, Hellborg H, Holm T. A population-based study on outcome in relation to the type of resection in low rectal cancer. Dis Colon Rectum 53(5):753-60

17. Stelzner S, Hellmich G, Schubert C, Puffer E, Haroske G, Witzigmann H. Short-term outcome of extra-levator abdominoperineal excision for rectal cancer. Int $\mathrm{J}$ Colorectal Dis 26(7):919-25

18. Asplund D, Haglind E, Angenete E. Outcome of extralevator abdominoperineal excision compared with standard surgery. Results from a single centre. Colorectal Dis. Jan 4

19. Welsch T, Mategakis V, Contin P, Kulu Y, Buchler MW, Ulrich A. Results of extralevator abdominoperineal resection for low rectal cancer including quality of life and long-term wound complications. Int J Colorectal Dis. Nov 21

20. Stelzner S, Koehler C, Stelzer J, Sims A, Witzigmann H. Extended abdominoperineal excision vs. standard abdominoperineal excision in rectal cancer-a systematic overview. Int J Colorectal Dis 26(10): $1227-40$

21. Krishna A, Rickard MJ, Keshava A, Dent OF, Chapuis PH. A comparison of published rates of resection margin involvement and intraoperative perforation between standard and "cylindrical" abdominoperineal excision for low rectal cancer. Colorectal Dis. Jul 3

22. Han JG, Wang ZJ, Wei GH, Gao ZG, Yang Y, Zhao BC. Randomized clinical trial of conventional versus cylindrical abdominoperineal resection for locally advanced lower rectal cancer. Am J Surg 204(3):274-82

23. Prytz M, Angenete E, Haglind E. Abdominoperineal extralevator resection. Dan Med J 59(9):A4366

24. Pahlman L, Bohe M, Cedermark B, Dahlberg M, Lindmark G, Sjodahl R et al (2007) The Swedish rectal cancer registry. Br J Surg 94(10):1285-1292

25. Jorgren F, Johansson R, Damber L, Lindmark G. Risk factors of rectal cancer local recurrence: population-based survey and validation of the Swedish rectal cancer registry. Colorectal Dis 12(10):977-86

26. Gunnarsson U, Seligsohn E, Jestin P, Pahlman L (2003) Registration and validity of surgical complications in colorectal cancer surgery. $\mathrm{Br}$ J Surg 90(4):454-459

27. Dindo D, Demartines N, Clavien PA (2004) Classification of surgical complications: a new proposal with evaluation in a cohort of 6336 patients and results of a survey. Ann Surg 240(2):205-213

28. Clavien PA, Barkun J, de Oliveira ML, Vauthey JN, Dindo D, Schulick RD et al (2009) The Clavien-Dindo classification of surgical complications: five-year experience. Ann Surg 250(2):187-196

29. van der Pas MH, Haglind E, Cuesta MA, Furst A, Lacy AM, Hop WC, et al. Laparoscopic versus open surgery for rectal cancer (COLOR II): short-term outcomes of a randomised, phase 3 trial. Lancet Oncol 14(3):210-8

30. Ng SS, Leung KL, Lee JF, Yiu RY, Li JC, Teoh AY et al (2008) Laparoscopic-assisted versus open abdominoperineal resection for low rectal cancer: a prospective randomized trial. Ann Surg Oncol 15(9):2418-2425

31. Jayne DG, Guillou PJ, Thorpe H, Quirke P, Copeland J, Smith AM et al (2007) Randomized trial of laparoscopic-assisted resection of colorectal carcinoma: 3-year results of the UK MRC CLASICC Trial Group. J Clin Oncol 25(21):3061-3068 